\title{
CONSIDERAÇÕES SOBRE A NEUTRALIDADE DA CIÊNCIA ${ }^{1}$
}

\author{
Marcos BARBOSA DE OLIVEIRA ${ }^{2}$
}

- RESUMO: O texto apresenta uma discussão da tese da neutralidade da ciência, tomando como ponto de partida algumas formulações dos Parâmetros Curriculares Nacionais. A neutralidade é analisada em três componentes: a imparcialidade, a neutralidade aplicada e a neutralidade cognitiva. Procura-se mostrar que, para não se cair no relativismo, a imparcialidade deve ser mantida, mas a neutralidade aplicada não se sustenta, nem como fato nem como valor.

- PALAVRAS-CHAVE: Ciência; tecnologia; neutralidade; relativismo; imparcialidade; Lacey.

Nosso tema é a neutralidade da ciência. Trata-se de um tema muito vasto e, como o título desta apresentação indica, não pretendo de forma alguma discutir cada uma de suas facetas, meu objetivo é apenas desenvolver algumas considerações, sumárias e parciais sobre ele.

Quanto à sua atualidade, acho que não é necessário dizer muito. Qualquer pessoa que acompanhe, ainda que por alto, aquilo que se anda dizendo sobre a ciência, com certeza terá encontrado com freqüência a afirmação de que a ciência não é neutra. Para tornar a exposição mais concreta, resolvi tomar como ponto de partida um texto em particular onde a tese da não-neutralidade é afirmada com muita ênfase, a saber, o texto dos Parâmetros Curriculares Nacionais, nas partes referentes ao

1 Palestra proferida como parte da programação do III Encontro Internacional de Informação, Conhecimento e Aprendizagem, realizado na UNESP - Campus de São Vicente, de 7 a 9 de dezembro de 2001

2 Professor Associado na Faculdade de Educação, Universidade de São Paulo. 
ensino de ciências naturais. Quando me dirijo a uma audiência de educadores estas explicações são dispensáveis, mas como este não é o caso aqui, convém esclarecer que os Parâmetros Curriculares Nacionais (popularmente conhecidos como $P C N$ ) são o resultado de uma iniciativa do Ministério da Educação, na gestão do ministro Paulo Renato, e referem-se ao ensino fundamental e médio. Seu objetivo é o de fornecer diretrizes para as várias facetas da prática educativa - conteúdos, métodos de ensino e avaliação, etc. Os Parâmetros se materializam numa série de volumes publicados pelo ministério a partir de 1997, e distribuídos a todas as escolas do país. Embora não possuam força de lei, eles têm um peso considerável, seu sentido é o de que o governo espera que todos os trabalhadores envolvidos com a educação - professores, coordenadores pedagógicos, diretores - façam o máximo para transformar suas recomendações em realidade.

Desde o início de sua publicação, os $P C N$ têm sido objeto de uma intensa polêmica, e é impressionante, por exemplo, o número de dissertações e teses sobre eles que vêm sendo produzidas nos programas de pós da área de Educação. A maioria desses trabalhos têm a natureza de críticas, e a crítica mais geral refere-se ao processo de elaboração dos textos, que teria sido pouco democrático, ao não levar na devida conta as experiências e as condições de trabalho daqueles que estão realmente com a mão na massa, em particular os professores. Resultaria daí uma enorme falta de realismo nas diretrizes prescritas. Para evitar malentendidos, quero dizer que subscrevo tais críticas, além de outras objeções que têm sido levantadas. Uma posição como essa não impede, entretanto, que se reconheçam nos $P C N$ aspectos positivos, e um destes diz respeito ao nosso tema - a questão da neutralidade da ciência - ao qual podemos agora retornar.

Na verdade, são surpreendentemente avançadas, a meu ver, as concepções sobre a ciência e a tecnologia defendidas nos $P C N$. Os $P C N-$ de maneira geral, não somente as partes referentes às ciências naturais tomam como uma de suas premissas a idéia da educação para a cidadania, ou seja, a tese de que além da formação necessária para o trabalho, para o exercício de cada profissão, a educação deve contribuir para formação de cidadãos, com tudo o que isso implica em termos de informação, da capacidade de refletir, de pensar com a própria cabeça, de participar na vida pública, etc. Juntando esta premissa com a constatação da enorme importância da ciência e da tecnologia no mundo de hoje, do impacto que essas práticas têm em incontáveis aspectos de nossa vida, tira-se a conclusão de que o ensino da ciência não pode se limitar a seus 
aspectos por assim dizer "internos" - isto é, a suas teorias, experimentos e métodos - mas deve explorar também seu papel na sociedade. Nos termos dos próprios $P C N$ :

Numa sociedade em que se convive com a supervalorização do conhecimento científico e com a crescente intervenção da tecnologia no dia-a-dia, não é possível pensar na formação de um cidadão crítico à margem do saber científico.

É importante que se supere a postura "cientificista" que levou durante muito tempo a considerar-se o ensino de Ciências como sinônimo da descrição de seu instrumental teórico ou experimental, divorciado da reflexão sobre o significado ético dos conteúdos desenvolvidos no interior da Ciência e suas relações com o mundo do trabalho. (PCN, 1997, p.23-4)

É como manifestação desta postura crítica que os $P C N$ enunciam a tese da não-neutralidade da ciência. Já na "Apresentação" do volume em pauta, p. ex., lê-se: “....este documento ... debate a importância do ensino de Ciências Naturais para a formação da cidadania, [e] caracteriza o conhecimento científico e tecnológico como atividades humanas, de caráter histórico e, portanto, não-neutras. (Ibidem, p.15, itálico acrescentado) E mais adiante: "Aos professores cabia a transmissão de conhecimentos acumulados pela humanidade, por meio de aulas expositivas, e aos alunos, a absorção das informações. O conhecimento científico era tomado como neutro e não se punha em questão a verdade científica." (Ibidem, p.19, itálico acrescentado) E, para dar um último exemplo: “...é intenção deste texto oferecer aos educadores alguns elementos que lhes permitam compreender as dimensões do fazer científico, sua relação de mão dupla com o tecnológico e o caráter não-neutro desses fazeres humanos". (Ibidem, p.26, itálico acrescentado)

Há ainda várias outras passagens deste teor, mas estas, acredito, já são suficientes para trazer à tona aquilo que interessa. Porém agora vem a pergunta: o que se quer dizer quando se afirma que a ciência e a tecnologia não são neutras? Se estamos falando de fenômenos elétricos, nós sabemos o que significa dizer que um corpo é neutro, que o nêutron, por exemplo, é neutro. No domínio da química, sabemos que uma substância é neutra quando não é nem ácida nem alcalina. Mas dizer que a ciência não é neutra, o que isto pode significar?

Os $P C N$ não deixam isso claro; não há em parte alguma uma definição que estabeleça com um mínimo de rigor o significado da tese da não-neutralidade. $\mathrm{O}$ contexto fornece algumas indicações, mas talvez $\mathrm{o}$ máximo que se possa tirar delas é que a tese da não-neutralidade deve ser 
interpretada como um convite, ou uma exortação para que se discuta, se examine criticamente o papel da ciência na sociedade, seu impacto sobre nossas vidas.

Nada tenho a objetar contra isso, muito pelo contrário, mas acho por outro lado que, para realizar concretamente esse exame, é essencial estabelecer uma definição mais precisa. O que se segue a partir de agora são alguns passos rumo a este objetivo. Para começar, vou enunciar dois pré-requisitos que uma definição adequada deve satisfazer. O primeiro é que de acordo com ela a tese deve - para usar uma expressão inglesa - ter dentes, deve incorporar o espírito crítico em relação ao papel social da ciência. O segundo requisito é o de que ela não implique alguma forma de relativismo. Isto é importante porque formulações relativistas da tese da não-neutralidade são muito comuns, especialmente na corrente pós-moderna de crítica à ciência, e estas, a meu ver, tendem a alienar muitas pessoas que, embora vendo com simpatia o questionamento da ciência, são repelidas pelo irracionalismo implícito nas formulações relativistas.

O grande problema do relativismo é seu caráter incoerente e, em conseqüência, auto-destrutivo. Não há razão para que o princípio relativista não seja aplicado a si próprio. Se não existe verdade objetiva, se todo conhecimento é relativo a valores e interesses, então a própria afirmação de que isso é assim é também relativa, e seu reconhecimento uma questão de preferência pessoal. Desta forma, o relativista nada teria a dizer ao anti-relativista para fazê-lo mudar de idéia, e o relativismo se esvaziaria de boa parte de seu conteúdo.

Para o racionalista, este argumento pode parecer absolutamente conclusivo. O problema entretanto é que, por um lado, ele já é conhecido há muito tempo - pelo menos desde os tempos de Platão - e é mobilizado com bastante freqüência, em inúmeras versões, a maioria delas muito mais eloqüente do que esta formulação extremamente abstrata e esquemática que acabei de apresentar. Por outro lado, a mobilização freqüente do argumento não tem estancado a difusão do relativismo.

A esta situação aplica-se bem o que se pode chamar de "princípio da razão insuficiente" - o princípio segundo o qual não adianta nada ter razão, se não conseguimos persuadir nossos interlocutores. $\mathrm{O}$ racionalista coerente não pode simplesmente dar de ombros, e se contentar com a convicção de que ele está certo, e o relativista está errado, pois esta desistência de procurar um consenso significa, na prática, uma vitória do irracionalista. 
Diante do impasse, há pelo menos duas alternativas. A primeira consiste em procurar formulações ainda mais persuasivas do argumento do caráter auto-destrutivo do relativismo, assim como de outros argumentos anti-relativistas. Depois de tantas tentativas fracassadas ao longo de mais de dois mil anos, esta a meu ver não é uma alternativa promissora. A outra, que será adotada aqui, consiste numa estratégia de três etapas. A primeira é entender as motivações que levam tantas pessoas a adotarem posições relativistas; a segunda é identificar o que há de positivo nestas motivações, e a terceira é mostrar como é possível contemplar este lado positivo das motivações sem cair no relativismo.

Tudo isso está dito de uma forma muito abstrata; para tornar estas afirmações mais inteligíveis, voltemos à nossa questão central, a da neutralidade da ciência. Fomos levados a discutir o relativismo porque, em algumas de suas possíveis interpretações, a tese da não-neutralidade da ciência é uma tese relativista. Como observei anteriormente, o máximo que o texto dos $P C N$ nos permite dizer, em termos de interpretação da tese da não-neutralidade, é que ela deve ser entendida como um convite ao questionamento do papel da ciência e da tecnologia no mundo contemporâneo. Aceitando a premissa de que este questionamento deve de fato ser promovido, já posso realizar os dois primeiros passos da estratégia de três, dizendo que o que há de positivo nas motivações que levam algumas pessoas a adotar a tese da não-neutralidade em alguma versão relativista é esta postura crítica diante da ciência, claramente identificável na corrente pós-moderna.

O terceiro passo da estratégia torna-se então o objetivo a ser perseguido, qual seja, o de especificar um significado para a tese da não-neutralidade que preserve seu espírito crítico, sem cair no relativismo.

Um filósofo cujas reflexões têm se dirigido a esse objetivo é Hugh Lacey. Lacey é um filósofo da ciência australiano de nascimento, há muito radicado nos Estados Unidos, mas que mantém uma relação muito estreita com o Brasil. Foi professor do Departamento de Filosofia da USP de 1969 a 1971, e desde essa época nos visita com freqüência para dar cursos, participar de eventos, bancas, etc. Lacey publicou dois livros recentemente: um em português, Valores e atividade científica, pela Discurso Editorial, em 1998, e outro em inglês, Is science value free? Values and scientific understanding, pela Routledge, em 1999. O primeiro é uma coletânea de artigos, o segundo é um livro propriamente dito, que desenvolve de maneira mais sistemática e rigorosa os temas abordados nos artigos do primeiro. O motivo para mencionar Lacey é o de que a par- 
tir de agora vou incorporar a esta reflexão alguns dos princípios que compõem sua estratégia visando o objetivo em pauta. Vou enunciar estes princípios numa terminologia que difere um pouco da usada por ele; os motivos para a alteração não vêm ao caso no momento. Então:

1 O conceito de neutralidade da ciência, num sentido amplo, deve ser analisado em alguns componentes, um dos quais é a imparcialidade.

2 Outro dos componentes da neutralidade no sentido o amplo é a neutralidade no sentido estrito, que por sua vez é formada pela neutralidade aplicada e a neutralidade cognitiva.

3 O relativismo é evitado pela afirmação da tese da imparcialidade, ou seja, a tese de que a ciência, nos termos a serem especificados, é imparcial; o espírito crítico é mantido pela tese da não-neutralidade no sentido estrito, ou seja, pela afirmação de que a ciência não tem como atributos nem a neutralidade cognitiva nem a neutralidade aplicada.

Vejamos então em que consiste a imparcialidade. A imparcialidade diz respeito ao processo de seleção de teorias no interior da ciência, ou seja, dado um conjunto de teorias rivais sobre um domínio da realidade, como decidimos qual delas é a melhor, qual deve ser aceita como parte do conhecimento científico? A resposta de Lacey para esta pergunta baseia-se numa distinção muito fundamental, a distinção entre valores cognitivos e valores não-cognitivos. Os valores não-cognitivos são os valores sociais e morais, ou, em outras palavras, os valores subentendidos quando se afirma que a ciência é livre de valores. Os valores cognitivos formam um conjunto do qual o mais importante, seguindo a tendência empirista que acabou prevalecendo na epistemologia moderna, é a adequação empírica, a capacidade de uma teoria de dar conta dos dados observacionais e experimentais disponíveis. Outros valores cognitivos importantes: são a consistência lógica, o poder explicativo, a simplicidade, etc.

Com isso podemos definir o conceito de imparcialidade: a imparcialidade consiste no uso exclusivo de valores cognitivos na seleção de teorias. Na medida em que há interferência de valores não-cognitivos, a ciência deixa de ser imparcial. Com o conceito de imparcialidade podem ser formuladas duas teses sobre a ciência: uma normativa - a ciência deve ser imparcial -; outra descritiva, ou factual - a ciência é imparcial. A tese normativa por um lado pressupõe que a ciência pode ser imparcial, por outro ela é compatível com a negação, pelo menos até certo ponto, da tese factual, ou seja, o fato de a ciência às vezes se afastar do ideal de imparcialidade não implica que o ideal deva ser abandonado - da 
mesma forma, por exemplo, que o fato de o mandamento "não matarás" nem sempre ser obedecido não implica que ele deva ser revogado.

As versões mais radicais da tese da não-neutralidade são as que abrem mão inclusive do ideal de imparcialidade, sustentando ser impossível excluir os valores não-cognitivos do processo de seleção de teorias no interior da ciência. Nesta linha de pensamento, a ciência não apenas sempre foi e continua sendo parcial, mas o próprio ideal de imparcialidade deixa de fazer sentido. $\mathrm{O}$ grande problema com este radicalismo é o que já foi apontado, a saber, que ele implica uma forma de relativismo. Se quisermos evitar o relativismo, devemos portanto preservar a imparcialidade como um ideal, ou seja, como um valor. É apenas desta maneira, inclusive, que se terá uma base para fazer uma crítica da ciência quando ela deixa de ser imparcial.

Com isso dou por encerrada a discussão da imparcialidade, e passo à neutralidade no sentido estrito, que, como vimos, divide-se em neutralidade aplicada e neutralidade cognitiva. A neutralidade cognitiva constitui um tema bem mais complexo que, devido à limitação de tempo, escapa dos limites desta apresentação, e será tratado numa outra oportunidade.

A neutralidade aplicada diz respeito às aplicações da ciência, ou seja, à tecnologia. Os termos em que a discussão é posta nos dias de hoje derivam em grande parte de uma versão particular da tese da neutralidade no sentido amplo, surgida num momento histórico determinado. Trata-se de uma versão em que a neutralidade da ciência é afirmada em contraste com a tecnologia, cuja não-neutralidade é admitida. O momento histórico é o do pós-segunda-guerra-mundial, e neste ponto vou recorrer a um livreto recentemente publicado, Thomas Kuhn and the Science Wars, de Ziauddin Sardar. Sardar diz o seguinte:

Na percepção popular da ciência, a segunda guerra mundial completou o que a primeira havia iniciado. Desta vez, via-se a ciência dirigindo o espetáculo no campo de batalha, e participando dos governos. Os cientistas eram responsáveis não apenas pela invenção de formas novas e mais letais de armas químicas e biológicas, mas por conceber, produzir e finalmente lançar a bomba atômica. As nuvens em forma de cogumelo das bombas jogadas sobre Hiroshima e Nagasaki significaram o fim da era da inocência científica. Agora a conexão entre ciência e guerra havia se tornado mais que evidente, a cumplicidade entre a ciência e a política tinha vindo à tona, e todas as noções de autonomia científica haviam evaporado. O público, que até então havia prestado atenção em grande parte nos benefícios da ciência, viu-se de repente tendo de encarar seu lado devastador. 
O processo contra a ciência militarizada começou com o lançamento da publicação dissidente chamada Bulletin of the Atomic Scientists por um grupo de físicos nucleares totalmente desencantados com o Projeto Manhattan nos Estados Unidos, e se consolidou com o surgimento do CND (a Campanha pelo Desarmamento Nuclear) no fim do anos 50. [...] Muitos cientistas estavam preocupados, querendo que a Bomba não fosse vista como uma conseqüência inevitável da física. [...] A tática consistia em alegar que a ciência é neutra; é a sociedade que a pode usar para o bem ou para o mal. Este argumento da neutralidade tornou-se a principal defesa da ciência durante as décadas de 50 e 60 ; e permitiu que muitos cientistas trabalhassem em física atômica, até mesmo aceitando financiamentos de órgãos militares, sem que deixassem de se considerar politicamente radicais. (Sardar, 2000, p.13-4)

Como se pode ver então, a conjuntura histórica pós-segunda-guerramundial gerou uma formulação particular da tese da neutralidade da ciência em que ela aparece contrastada com a não-neutralidade de suas aplicações, que podem ser voltadas para o bem ou para o mal. Esta perspectiva tem em princípio certa validade. Não há dúvida de que não apenas a ciência, mas qualquer artefato humano admite diferentes formas de utilização. Uma faca de cozinha, por exemplo, pode ser usada "para o bem" - para, digamos, descascar batatas - ou para torturar ou assassinar uma pessoa, e neste sentido ela é neutra. Entretanto, como um ponto de vista para a avaliação dos benefícios e malefícios da ciência aplicada, ela deixa muito a desejar. Deixa a desejar porque de acordo com ela, como no caso paradigmático da bomba atômica, o mal figura como intenção explícita. Se nos limitarmos a casos desta natureza, deixaremos de enxergar os aspectos perniciosos das utilizações da ciência que não fazem parte das intenções daqueles que as promovem, mas nem por isso são menos importantes. Dentre os malefícios não-intencionais, vou distinguir três categorias: 1) Os correspondentes aos efeitos colaterais, 2) os correspondentes às pré-condições sistêmicas, e 3) Os correspondentes ao que os economistas chamam de custo de oportunidade, que daqui a pouco vou explicar em que consiste.

Os efeitos colaterais são os mais fáceis de entender. Considerada apenas do ponto de vista de sua conveniência, não há dúvida de que as geladeiras são uma grande invenção, que facilita muito a vida das pessoas. Porém os gases usados nos sistemas de refrigeração das geladeiras, pelo menos até recentemente, contribuem para a destruição da camada de ozônio. É evidente que para avaliar até que ponto geladeiras são "do bem", ou "do mal", não se pode desconsiderar este efeito. Em relação à tecnologia como um todo, há uma quantidade enorme de efeitos colate- 
rais a serem levados em conta. Eles incluem as inúmeras formas de destruição e degradação do meio ambiente, incluem perturbações sociais, como por exemplo o desemprego, problemas de saúde causados pelos aditivos químicos presentes em alimentos industrializados, incluem o efeito estufa ... enfim, não é necessário ficar chovendo no molhado: acredito que nenhum de vocês terá dificuldade em acrescentar novos itens a essa lista.

Além destes, há ainda um outro tipo de conseqüência negativa das inovações tecnológicas que convém incluir na categoria dos efeitos colaterais, embora isto envolva talvez uma ampliação do conceito. Estou me referindo aos problemas éticos, como os associados às técnicas de clonagem dos seres humanos, muito em evidência recentemente. Não estou querendo dizer que a humanidade deva recusar o desafio representado por tais dilemas, rejeitando in limine qualquer inovação que possa provocá-los. Mas é preciso não perder de vista que esses problemas são bem reais, eles demandam uma considerável dose de energia para serem resolvidos. Não uma energia que possa ser contabilizada em dólares; uma energia espiritual, ou emocional, mas nem por isso menos significativa. Também não estou querendo dizer que esse dispêndio não possa ser compensador. No caso da pílula anticoncepcional, para tomar um outro exemplo, pode-se argumentar que sua invenção também deu origem a um problema ético, mas - em que pesem as resistências ainda mantidas pela Igreja Católica - que este já foi superado, e que no processo milhões de mulheres e homens se beneficiaram com a libertação sexual tornada viável pela pílula. Mas serão os dilemas colocados pela clonagem tão fáceis de serem resolvidos? Será comparável o número de pessoas a serem beneficiadas? Ou, em outras palavras, será que este tipo de inovação não cria mais problemas do que resolve?

O segundo tipo de malefício não-intencional da tecnologia resulta do fato de que algumas aplicações tecnocientíficas exigem para sua implementação determinadas pré-condições sociais. Se estas não estão presentes nas sociedades em que se planeja introduzir a inovação, é preciso promover as necessárias mudanças, as quais podem ter conseqüências negativas, previstas ou não. Tais conseqüências devem naturalmente ser levadas em conta para se fazer o balanço dos benefícios e malefícios decorrentes da inovação. Para ilustrar essas formulações abstratas, um bom exemplo é o da chamada Revolução Verde, em que as alterações sociais necessárias para viabilizar a introdução de técnicas agrícolas baseadas no uso de variedade híbridas de cereais foram tão desastrosas que no cômputo geral agravaram em vez de resolver os problemas da 
fome nas regiões onde foi promovida, apesar do aumento de produtividade conseguido (produtividade medida apenas em termos de toneladas por hectare). ${ }^{3}$

Passemos agora ao terceiro item de nossa lista, a saber, ao custo de oportunidade. Esse conceito dos economistas refere-se ao processo de tomada de decisões relativas à aplicação de recursos. A idéia, muito sensata, é a de que a racionalidade de uma determinada aplicação de recursos não pode ser estabelecida a partir de uma análise custo-benefício que leve em conta apenas o montante dos recursos e o valor dos benefícios esperados. Não pode porque é necessário considerar também os benefícios que resultariam de aplicações alternativas. Para dar um exemplo bem simples, a decisão de adquirir um telefone celular por parte de uma família pode parecer racional se considerada isoladamente, mas não se a família estiver em dificuldades financeiras e tiver de deixar de comprar alimentos para adquirir o celular. O custo de oportunidade do celular inclui assim, como elemento negativo, evidentemente, o benefício de poder se alimentar, que seria decorrência da decisão alternativa de aplicar o recurso na compra de comida.

Embora seja de uma sensatez cristalina, o princípio do custo de oportunidade é muitas vezes escandalosamente esquecido. Há um tempo atrás, por exemplo, houve uma grande controvérsia sobre a instalação de uma fábrica da Ford no Rio Grande do Sul. Os defensores do projeto apregoavam insistentemente o número de empregos que seriam criados, mas faziam questão de deixar na obscuridade o número de novos empregos que resultariam de aplicações alternativas dos recursos, por exemplo, no financiamento de pequenos produtores rurais, ou na construção civil.

Aplicado à tecnologia, o princípio do custo de oportunidade dá origem a perguntas como esta: será que, do ponto de vista das condições de saúde da totalidade dos seres humanos, os recursos destinados às pesquisas de alta tecnologia, que na maioria dos casos são acessíveis apenas às camadas mais ricas, não teriam um retorno muito maior se aplicados na eliminação das causas dos problemas de saúde da imensa maioria pobre da população do mundo?

Ou então consideremos a pesquisa agroecológica voltada para a produção orgânica de alimentos, em comparação com a biotecnológica relacionada aos transgênicos. Assumindo não o critério limitado de produtividade medida em toneladas por hectare, mas um critério amplo, que

3 Cf. Shiva (1991). Para um estudo da Revolução Verde como exemplo de falta de neutralidade nas práticas tecnocientíficas, v. Lacey (1998), p. 79ss., e Lacey (1999), p.189ss. 
inclua a dimensão dos riscos, bem como os impactos ambientais e sociais dos métodos alternativos, será a pesquisa biotecnológica de fato mais vantajosa que a agroecológica? ${ }^{4}$

Para concluir esta parte da exposição, eu diria que, quando se deixam de lado esses três tipos de consideração, a defesa da alta tecnologia é trivial, quase tautológica; fica muito fácil taxar os críticos de obscurantistas, retrógrados ou mesmo ludditas. Quando eles são levados em conta, é possível devolver a acusação. Obscurantista é quem se recusa a discutir o papel social da ciência e da tecnologia, obscurantistas são os países que embarcam cegamente nesta corrida de ratos pelo sucesso científico e tecnológico, apesar do visível risco de que ela venha a terminar num abismo.

Mas neste ponto, alguém poderá levantar a seguinte objeção: o tema central em pauta é o da neutralidade ou não-neutralidade da ciência. Esta última série de considerações diz respeito não à ciência, mas à tecnologia. Não seria então possível aceitá-las todas, e ao mesmo tempo continuar sustentando a tese da neutralidade da ciência?

A resposta a este questionamento baseia-se numa constatação que vem a cada dia se tornando mais um lugar comum, a saber, a de que nos últimos tempos a ciência e a tecnologia têm tantas dependências mútuas, estão tão imbricadas uma na outra que a separação entre os dois domínios vai se tornando impossível. Um entre os vários sintomas deste processo é o neologismo tecnociência, de uso cada vez mais freqüente. Nessas condições, a não-neutralidade da tecnologia por assim dizer contamina também a ciência. O grau de imbricação não é uniforme ao longo dos vários domínios. Atinge um máximo na biotecnologia, em setores mais tradicionais é menor. Embora a média geral seja alta, há um grau de não-neutralidade aplicada em cada domínio que só pode ser estimada com base em estudos concretos de suas particularidades. A conclusão, em todo o caso, é a de que de maneira geral não se sustenta mais a estratégia de separar a ciência da tecnologia, admitindo a relevância dos valores sociais apenas para esta. Ou seja, no sentido da neutralidade aplicada, a ciência não é neutra. ${ }^{5}$

Para concluir, eu diria que, conforme os objetivos estabelecidos, esta tese da não-neutralidade aplicada atende o requisito de incorporar

\footnotetext{
4 Cf. Lacey (2002).

5 Para uma discussão mais elaborada sobre a realidade da tecnociência, v. Barbosa de Oliveira (no prelo), seção 2.
} 
uma visão crítica. Ela fornece um quadro de referência que permite aceitar o convite, ou exortação mencionados no início para que se examine criticamente o papel social da ciência e da tecnologia no mundo em que vivemos. Por outro lado - e isto pode ser demonstrado, se houver necessidade - ela não ameaça a tese da imparcialidade, necessária para evitar o relativismo. A meu ver, a análise proposta é então estruturalmente sólida. Vejamos agora se vocês concordam comigo.

BARBOSA DE OLIVEIRA, M. B. Considerations on the neutrality of science. Trans/Form/Ação, (São Paulo), v. 26, p.161-172, 2003.

- ABSTRACT: The work consists in a discussion of the thesis of neutrality of science and technology, which takes as its starting point some formulations in the Parâmetros Curriculares Nacionais. Neutrality is analised into three components: imparciality, applied neutrality and cognitive neutrality. It is shown that imparciality must be maintained, to avoid falling into relativism, but applied neutrality cannot be sustained, neither as fact nor as value.

- KEYWORDS: Science; technology; neutrality; relativism; imparciality; Lacey.

\section{Referências bibliográficas}

. Parâmetros Curriculares Nacionais, $1^{a}$ à $4^{a}$ séries da Educação Fundamental, vol. 4 - Ciências Naturais. Brasília: Ministério da Educação e do Desporto / Secretaria de Educação Fundamental, 1997.

LACEY, H. Valores e atividade científica. São Paulo: Discurso Editorial, 1998.

. Is science value free?: values and scientific understanding. Londres e Nova York: Routledge, 1999.

. A tecnociência e os valores do Fórum Social Mundial. In: LOUREIRO, I., CEVASCO, M.E. e LEITE, J.C. (org.), O espírito de Porto Alegre, São Paulo: Paz e Terra, 2002.

BARBOSA DE OLIVEIRA, M.B. Desmercantilizar a tecnociência. In: SANTOS, B.S. (org.). Um discurso sobre as ciências revisitado. São Paulo: Cortez, no prelo.

SARDAR, Z. Thomas Kuhn and the science wars. Cambridge: Icon Books, 2000.

SHIVA, V. The violence of the green revolution : third world agriculture, ecology and politics. Londres e Nova York: Zed Books, 1991. 